\title{
Management of non-arteritic anterior ischemic optic neuropathy
}

\author{
Sohan Singh Hayreh
}

Received: 5 August 2009 /Accepted: 20 August 2009/Published online: 30 September 2009

(C) Springer-Verlag 2009

\section{Introduction}

Non-arteritic anterior ischemic optic neuropathy (NA-AION) is one of the major causes of seriously impaired vision among the middle-aged and elderly population; in addition, contrary to popular belief, it also occurs in young persons, though less commonly. In spite of it being a common disease, almost all publications on NA-AION contain the following two statements: (1) "Pathogenesis of NA-AION is unknown." and (2) "There is no known treatment for NA-AION.". Given the current state of our knowledge on NA-AION, neither statement is correct, as will be evident from the following short discussion. (Both pathogenesis and management of NAAION are discussed at length elsewhere [1, 2]).

Management of NA-AION has been highly controversial. Various treatments for NA-AION have been advocated from time to time, but were found to be useless and even, in some cases, harmful. To evaluate the validity of any treatment, there are two essential considerations: (1) it must have a scientific rationale; any treatment without that, irrespective of how aggressively it is advocated and how attractive it may seem, is not going to work in the long run, as was demonstrated by optic nerve sheath decompression in NA-AION, and (2) treatment of a disease must arise from full understanding of its pathogenesis.

\footnotetext{
S. S. Hayreh

Department of Ophthalmology and Visual Sciences,

College of Medicine, University of Iowa,

Iowa City, IA, USA

S. S. Hayreh $(\bowtie)$

Department of Ophthalmology and Visual Sciences,

University Hospitals \& Clinics,

200 Hawkins Drive,

Iowa City, IA 52242-1091, USA

e-mail: sohan-hayreh@uiowa.edu
}

\section{Pathogenesis of NA-AION}

Etiologically and pathogenetically, NA-AION is of two types. One, by far the most common, is caused by transient nonperfusion or hypoperfusion of the optic nerve head $(\mathrm{ONH})$ circulation; the second, and rarer type is due to embolic lesions of the arteries/arterioles feeding the $\mathrm{ONH}$. The pathogenesis of NA-AION is discussed at length elsewhere $[1,2]$. Briefly, all the available evidence indicates that NA-AION is multifactorial in nature. The risk factors fall into two main categories:

1. Predisposing risk factors: these may be systemic or local in the eye and/or ONH. They make the $\mathrm{ONH}$ susceptible to ischemic disorders, but do not necessarily produce NA-AION by themselves.

(a). Systemic risk factors: NA-AION patients, compared to the general population, have a significantly higher prevalence of arterial hypertension, nocturnal arterial hypotension, diabetes mellitus, ischemic heart disease and other cardiovascular disorders, hyperlipidemia, atherosclerosis and arteriosclerosis [1, 3-7]. Other associated systemic diseases have also been reported, including sleep apnea [1, 8-10], arterial hypotension due to a variety of causes [11] and malignant arterial hypertension [12], and migraine.

(b). Ocular and ONH risk factors: NA-AION is significantly associated with absent or small cup in the optic disc [13, 14], location of the watershed zone of the posterior ciliary arteries in relation to the optic disc [15], and vascular disorders in the nutrient vessels of the $\mathrm{ONH}$ [16], optic disc drusen and cataract extraction [17]. Other risk factors include markedly raised intraocular pressure [17], and marked optic disc edema due to any cause 
[18]. Contrary to the prevalent impression, an absent or small cup is simply a secondary contributing factor, once the process of NA-AION has started, and NOT a primary factor [13, 14, 19].

2. Precipitating risk factor(s): in a person with predisposing risk factors already present, these risk factors act as the final insult ("last straw"), resulting in ischemia of the ONH and NA-AION. Studies have shown that patients with NA-AION typically complain of discovering visual loss on waking in the morning. In one study, 73\% NAAION patients gave a definite history of discovering the visual loss on waking up in the morning or from a nap, or one the first opportunity in the day to use vision critically [20]. The incidence may actually be much higher than $73 \%$, because many patients were not certain about the time of the day when they discovered the visual loss. Therefore, nocturnal arterial hypotension is the most important factor in this category [20-22]; its role is discussed at length elsewhere [1, 2]. Studies have also shown that arterial hypertensives on oral hypotensive therapy have a significant $(p=0.004)$ association between progressive visual field deterioration in NA-AION and nocturnal hypotension $[21,22]$.

Serious confounding factors in determining risk factors for NA-AION

1. One of the arguments often put forward by those who believe the pathogenesis of NA-AION is not known is that some patients with NA-AION are perfectly healthy and have no known risk factors. Inability to find a risk factor may be due to several reasons. For example, a totally asymptomatic person, who looks perfectly healthy and feels fine, whose routine physical evaluation does not reveal any systemic, ocular or ONH abnormality may still have risk factors. I have recently found out that fact from an unpleasant personal experience. Recently I had a Holter monitor to record electrocardiogram for a minor reason when I was totally asymptomatic, feeling fine and working perfectly normally. The monitor showed that during the night I was having frequent, recurrent and prolonged periods of complete asystole (with a flat electrocardiogram), some lasting as long as 10 seconds; occasionally the asystoles also occurred during the day. That required urgent pacemaker implantation to prevent me from going into cardiac arrest. The monitoring was done essentially because I am a physician and the cardiologist is my colleague and friend; it would have never been done normally. This clearly shows the fallacy in assuming that a perfectly healthy-looking person does not have any risk factors.

2. In 24-hour ambulatory BP recording in about 800 patients, I often found patients whose blood pressure was ideal during the waking hours, but dropped to very low levels during sleep. Thus, normal blood pressure during the waking hours is no guide to the blood pressure during sleep.

3. Derangement of autoregulation of the ONH blood flow is suspected to play an important role in various types of circulatory disorders of the ONH. Unfortunately, we have no means of evaluating that so far.

Thus, the axiom should be that if one does not find any evident risk factor, that does not necessarily mean that person actually has no risk factor.

Clearly, a whole host of systemic and local factors, acting in different combinations and to different extents may derange the $\mathrm{ONH}$ circulation, with some making the ONH susceptible to ischemia and others acting as the final insult. Nocturnal hypotension seems to be an important precipitating factor in the susceptible patient. Contrary to common misconception, NA-AION is not a thromboembolic disorder in the vast majority of cases.

Thus, the pathogenesis of NA-AION is complex but not, as often stated, unknown.

\section{Management of NA-AION}

The main treatments which have been advocated for NA-AION over the recent years are:

Optic nerve sheath decompression Sergott et al. [23] in 1989 claimed that optic nerve sheath decompression improved visual function in "progressive" NA-AION. The procedure gained world-wide favor not only in "progressive" but also in all types of NA-AION, in spite of the fact that it was pointed out [24] that this procedure had no scientific rationale and may be harmful. A multicenter clinical trial conducted by the United States' National Institutes of Health subsequently established that this procedure is "not effective" and "not an appropriate treatment for non-arteritic AION" and "may be harmful", because $24 \%$ of the eyes with optic nerve sheath decompression suffered further visual loss, as compared to only $12 \%$ simply left alone [25]. This and another study [26] showed that $41 \%-43 \%$ of cases showed spontaneous visual acuity improvement, without any procedure.

Aspirin This has been advocated with the mistaken impression that NA-AION, like stroke, is a thromboembolic disorder which has not been supported by the available studies. For example, two large studies have revealed no long-term benefit from aspirin in reducing the risk of NAAION in the fellow eye [27, 28], because aspirin has no effect on nocturnal arterial hypotension. 
Levodopa Johnson et al. [29, 30], in a retrospective study of patients with NA-AION, concluded that "levodopa appears to be beneficial in the treatment of recent-onset NAION" [30]. However, this conclusion was not valid, as discussed in detail elsewhere [31, 32]. First, there is no scientific rationale for the use of levodopa in NA-AION, and second, there were serious statistical problems with their data analysis, because the results of this study were not interpretable in view of the potential confounding and biases that were apparently present.

Systemic corticosteroid therapy A recent large, prospective study [33], based on 696 eyes, comparing the visual outcome in treated (364 eyes) versus untreated control (332 eyes) groups, with identical baseline parameters in the two groups, concluded that NA-AION eyes treated during the acute phase with systemic corticosteroids had a significantly higher probability of improvement in visual acuity and visual field than did the untreated group. In eyes with initial visual acuity of $20 / 70$ or worse, seen within 2 weeks of onset, there was visual acuity improvement in $70 \%$ in the treated group compared to $41 \%$ in the untreated group (odds ratio of improvement: 3.39; 95\% CI:1.62, 7.11; $p=0.001$ ). Similarly, among those seen within 2 weeks of NA-AION onset with moderate to severe initial visual field defect, there was improvement in $40 \%$ of the treated group and $25 \%$ of the untreated group (odds ratio: $2.06,95 \% \mathrm{CI}$ : 1.24, 3.40; $p=0.005)$. A comparison of treated versus untreated groups also showed that optic disc edema resolved significantly $(p=0.0006)$ faster in the treated group [34].

Use of intravitreal triamcinolone acetonide There have recently been two contradictory small studies on this topic. Jonas et al. [35], in three patients, found that it had no beneficial effect on visual acuity. Kaderli et al. [36], in four eyes, reported visual acuity improvement, but without any improvement in visual fields; however, that study had some notable flaws [37]. Briefly, these include: (a) their study was based on only four eyes, (b) two large natural history studies have shown spontaneous visual acuity improvement in $41 \%-43 \%$ of eyes with NA-AION $[25,26]$, and (c) more importantly, none of the eyes in the study by Kaderli et al. [36] showed improvement in visual fields and all had altitudinal visual field defects. Studies have shown that in NA-AION and arteritic AION apparent visual acuity improvement without visual field improvement is due to the patient learning to fixate eccentrically, rather than being a genuine visual improvement [26, 38]. In the study by Kaderli et al. [36], eccentric fixation may explain why the visual acuity of the patients apparently improved, while the visual fields did not.

Use of intravitreal bevacizumab A case report by Bennett et al. in 2007 [39] claimed visual improvement after an intravitreal injection of bevacizumab (Avastin) 3 weeks after the onset of NA-AION in one eye. The authors claim that bevacizumab - a vascular endothelial growth factor (VEGF) inhibitory drug - improved visual acuity in the eye by reducing optic disc edema. But it is impossible to judge the effectiveness of a mode of treatment from one eye when $41 \%-43 \%$ of NA-AION eyes show spontaneous visual acuity improvement. In contrast, recently there have been two reports where intravitreal bevacizumab injection actually resulted in the development of NA-AION. Hosseini and Razeghinejad [40] reported a 72-year-old woman who woke up with visual loss 1 week after intravitreal injection of bevacizumab, and was diagnosed to have NA-AION. In this issue of the Journal, Ganssauge et al. [41] report a 51-year-old male who "recognized" visual field defects 2 weeks after injection with intravitreal of bevacizumab for choroidal neovascularisation, and was diagnosed as having NA-AION.

In these two cases, it could be argued that because there was a time lag of 1 week and 2 weeks respectively between the intravitreal injection of bevacizumab and the "development" of NA-AION, the latter could not be attributed to the former. Since the patient of Ganssauge et al. [41] "recognized" the visual field defect, the possibility that it was there before and he was unaware cannot be ruled out. I have seen that in some patients with NA-AION. The patient of Hosseini and Razeghinejad [40] woke up with visual loss 1 week after the injection. There is an explanation for the delay between the intravitreal injection and development of visual loss due to NA-AION. In 1981 [42], I reported that asymptomatic optic disc edema is an early sign of NAAION. More recently, we described the clinical entity of "Incipient nonarteritic anterior ischemic optic neuropathy" in 55 eyes [19], in which, again, NA-AION patients were seen initially with asymptomatic optic disc edema, and $25 \%$ of them later on progressed to classical NAION with median time of progression of 5.8 (interquartile 3.2-10.1) weeks from the initial diagnosis.. Thus, contrary to the universal impression, the time of visual loss is not always the time of onset of NA-AION - it is only the time when the patient notices it. In these two cases [40, 41], the intravitreal injection most probably started the chain of events. It initially produced "Incipient nonarteritic anterior ischemic optic neuropathy"; however, the patients were seen by the ophthalmologist only when they developed and noticed visual loss 1-2 weeks later.

The whole subject of intravitreal injection of bevacizumab requires detailed discussion because of the current enthusiasm for the use of anti-VEGF drugs in all sorts of disorders in ophthalmology. Naturally the question arises: what is the mechanism of development of NA-AION following intravitreal injection of bevacizumab? The $\mathrm{ONH}$ circulation depends upon the perfusion pressure (Perfusion pressure $=$ 
mean blood pressure minus intraocular pressure) in its capillaries. Following intravitreal injection of anti-VEGF drugs, two types of rise of intraocular pressure (IOP) have been reported.

1. Short-term rise of IOP Intravitreal injection increases the volume in the eyeball, thereby resulting in a transient rise of IOP in all eyes. After intravitreal injection of bevacizumab, $\mathrm{Kim}$ et al. [43] reported a rise of IOP to $44 \mathrm{mmHg}$ (range, 4-87 mmHg.), Falkenstein et al. [44] a mean IOP of 36. $\mathrm{mmHg}$, and Hollands et al. [45] an IOP of $25 \mathrm{mmHg}$ or higher at 30 minutes, and one patient required a 1-week course of glaucoma medication to control the IOP. Semoun et al. [46] reported a case of an acute angle-closure glaucoma that occurred immediately after an intravitreal injection of $0.05 \mathrm{ml}$ of bevacizumab.

2. Severe and sustained ocular hypertension Bakri et al. [47] reported sustained ocular hypertension as high as 30, 34,46 , and $50 \mathrm{mmHg}$ in the four patients following $0.5 \mathrm{mg}$ intravitreal ranibizumab for age-related macular degeneration. The elevated IOP persisted across several visits, requiring control with topical glaucoma therapy, and in two cases the addition of a systemic carbonic anhydrase inhibitor. None of the patients had a previous history of glaucoma. Kahook et al. [48] reported six cases of significant and sustained elevation of $10 P$ after intravitreal injections of bevacizumab for agerelated macular degeneration, all requiring IOP-Iowering therapy. At the annual meeting of the ARVO in May 2009, there was another report (I do not remember the names of the authors) of four cases with similar persistent elevation of IOP following intravitreal injection of bevacizumab. Jalil et al. [49] reported a case that was found to have an IOP of $56 \mathrm{mmHg}$ 3 days after intravitreal injection of bevacizumab. Similarly, there are many reports showing a substantial rise in IOP a few days or weeks after intravitreal triamcinolone; by contrast, oral steroid therapy for NA-AION did not have that effect on IOP during a short-term treatment [33]. While sustained IOP rise has been recorded by these reports, we do not have information about how common it is after intravitreal ranibizumab, because the usual practice is to monitor IOP only immediately post-injection and not later on. It is possible that it may be more prevalent than reported in the literature.

In NA-AION, the ONH already has precarious circulation. Under those circumstances, even a transient high IOP, let alone a prolonged sustained high IOP, has the potential to further compromise the circulation and result in further $\mathrm{ONH}$ damage and visual loss. In patients who do not already have NA-AION, the chance of developing NA-AION with this transient or sustained high IOP is limited to those who are susceptible because of the predisposing risk factors discussed above. When treating age-related macular degeneration in those cases, on a risk/benefit ratio, it may be prudent to avoid any immediate or prolonged rise of IOP by taking precautionary measures. For persons who have already had NA-AION in one eye, the risk of the second eye developing NA-AION is much higher than for those who never had NAAION before. Thus, a high IOP can precipitate development of NA-AION in persons with predisposing risk factors, and can worsen the visual outcome in those with NA-AION. In view of that, intravitreal injections of anti-VEGF agents or of triamcinolone have the potential to be harmful in the management of NA-AION - a factor not realized in the current enthusiasm for widespread use of anti-VEGF agents, particularly a proposed treatment for NA-AION. Moreover, anti-VEGF agents on rare occasions have other ocular complications as well as systemic side-effects, e.g., acute elevation of systemic blood pressure, cerebrovascular accidents, myocardial infarctions, and even deaths have been reported in some cases [50].

\section{Conclusion}

1. The pathogenesis of NA-AION is highly complex but not unknown.

2. A recent large prospective study has shown that systemic corticosteroid therapy, given according to the regimen described in the original study, results in a significantly higher probability of improvement in visual acuity $(p=0.001)$ and visual field $(p=0.005)$ compared to the untreated group. Therefore, we do now have an effective treatment for NA-AION.

3. Anti-VEGF therapy in treatment of NA-AION has the potential to be harmful.

Acknowledgement I am grateful to Ms. Patrician Duffel, our librarian, for her expert help with the bibliography. My wife Shelagh was helpful in the preparation of this manuscript.

Conflict of interest The author has no conflict of interest.

\section{References}

1. Hayreh SS (1996) Acute ischemic disorders of the optic nerve: pathogenesis, clinical manifestations, and management. Ophthalmol Clin North Am 9:407-442

2. Hayreh SS (2009) Ischemic optic neuropathy. Prog Retin Eye Res 28:34-62

3. Repka MX, Savino PJ, Schatz NJ, Sergott RC (1983) Clinical profile and long-term implications of anterior ischemic optic neuropathy. Am J Ophthalmol 96:478-483

4. Guyer DR, Miller NR, Auer CL, Fine SL (1985) The risk of cerebrovascular and cardiovascular disease in patients with anterior ischemic optic neuropathy. Arch Ophthalmol 103:1136-1142

5. Hayreh SS, Joos KM, Podhajsky PA, Long CR (1994) Systemic diseases associated with nonarteritic anterior ischemic optic neuropathy. Am J Ophthalmol 118:766-780 
6. Jacobson DM, Vierkant RA, Belongia EA (1997) Nonarteritic anterior ischemic optic neuropathy. A case-control study of potential risk factors. Arch Ophthalmol 115:1403-1407

7. Hayreh SS, Zimmerman MB (2008) Nonarteritic anterior ischemic optic neuropathy: clinical characteristics in diabetic patients versus nondiabetic patients. Ophthalmology 115:1818-1825

8. Mojon DS, Hedges TR 3rd, Ehrenberg B, Karam EZ, Goldblum D, Abou-Chebl A, Gugger M, Mathis J (2002) Association between sleep apnea syndrome and nonarteritic anterior ischemic optic neuropathy. Arch Ophthalmol 120:601-605

9. Palombi K, Renard E, Levy P, Chiquet C, Deschaux C, Romanet JP, Pépin JL (2006) Non-arteritic anterior ischaemic optic neuropathy is nearly systematically associated with obstructive sleep apnoea. Br J Ophthalmol 90:879-882

10. Li J, McGwin G Jr, Vaphiades MS, Owsley C (2007) Non-arteritic anterior ischaemic optic neuropathy and presumed sleep apnoea syndrome screened by the Sleep Apnea scale of the Sleep Disorders Questionnaire (SA-SDQ). Br J Ophthalmol 91:15241527

11. Hayreh SS (1987) Anterior ischemic optic neuropathy. VIII. Clinical features and pathogenesis of post-hemorrhagic amaurosis. Ophthalmology 94:1488-1502

12. Hayreh SS, Servais GE, Virdi PS (1986) Fundus lesions in malignant hypertension. V. Hypertensive optic neuropathy. Ophthalmology 93:74-87

13. Beck RW, Servais GE, Hayreh SS (1987) Anterior ischemic optic neuropathy. IX. Cup-to-disc ratio and its role in pathogenesis. Ophthalmology 94:1503-1508

14. Hayreh SS, Zimmerman MB (2008) Nonarteritic anterior ischemic optic neuropathy: refractive error and its relationship to cup/disc ratio. Ophthalmology 115:2275-2281

15. Hayreh SS (1990) In vivo choroidal circulation and its watershed zones. Eye 4:273-289

16. Hayreh SS (1995) The 1994 Von Sallman Lecture. The optic nerve head circulation in health and disease. Exp Eye Res 61:259272

17. Hayreh SS (1980) Anterior ischemic optic neuropathy. IV. Occurrence after cataract extraction. Arch Ophthalmol 98:1410 1416

18. Hayreh SS (1977) Optic disc edema in raised intracranial pressure. VI. Associated visual disturbances and their pathogenesis. Arch Ophthalmol 95:1566-1579

19. Hayreh SS, Zimmerman MB (2007) Incipient nonarteritic anterior ischemic optic neuropathy. Ophthalmology 114:1763-1772

20. Hayreh SS, Podhajsky PA, Zimmerman B (1997) Nonarteritic anterior ischemic optic neuropathy: time of onset of visual loss. Am J Ophthalmol 124:641-647

21. Hayreh SS, Zimmerman MB, Podhajsky P, Alward WL (1994) Nocturnal arterial hypotension and its role in optic nerve head and ocular ischemic disorders. Am J Ophthalmol 117:603-624

22. Hayreh SS, Podhajsky P, Zimmerman MB (1999) Role of nocturnal arterial hypotension in optic nerve head ischemic disorders. Ophthalmologica 213:76-96

23. Sergott RC, Cohen MS, Bosley TM, Savino PJ (1989) Optic nerve decompression may improve the progressive form of nonarteritic ischemic optic neuropathy. Arch Ophthalmol 107:1743-1754

24. Hayreh SS (1990) The role of optic nerve sheath fenestration in management of anterior ischemic optic neuropathy. Arch Ophthalmol 108:1063-1065

25. The Ischemic Optic Neuropathy Decompression Trial Research Group (1995) Optic nerve decompression surgery for nonarteritic anterior ischemic optic neuropathy (NAION) is not effective and may be harmful. JAMA 273:625-632

26. Hayreh SS, Zimmerman MB (2008) Nonarteritic anterior ischemic optic neuropathy: natural history of visual outcome. Ophthalmology 115:298-305
27. Beck RW, Hayreh SS, Podhajsky PA, Tan ES, Moke PS (1997) Aspirin therapy in nonarteritic anterior ischemic optic neuropathy. Am J Ophthalmol 123:212-217

28. Newman NJ, Scherer R, Langenberg P, Kelman S, Feldon S, Kaufman D, Dickersin K, Ischemic Optic Neuropathy Decompression Trial Research Group (2002) The fellow eye in NAION: report from the ischemic optic neuropathy decompression trial follow-up study. Am J Ophthalmol 134:317-328

29. Johnson LN, Gould TJ, Krohel GB (1996) Effect of levodopa and carbidopa on recovery of visual function in patients with nonarteritic anterior ischemic optic neuropathy of longer than six months' duration. Am J Ophthalmol 121:77-83

30. Johnson LN, Guy ME, Krohel GB, Madsen RW (2000) Levodopa may improve vision loss in recent-onset, nonarteritic anterior ischemic optic neuropathy. Ophthalmology 107:521-526

31. Beck RW (2000) Does Levodopa improve visual function in NAION? Ophthalmology 107:1431-1434

32. Hayreh SS (2000) Does Levodopa improve visual function in NAION? Ophthalmology 107:1434-1438

33. Hayreh SS, Zimmerman MB (2008) Non-arteritic anterior ischemic optic neuropathy: role of systemic corticosteroid therapy. Graefes Arch Clin Exp Ophthalmol 246:1029-1046

34. Hayreh SS, Zimmerman MB (2007) Optic disc edema in nonarteritic anterior ischemic optic neuropathy. Graefes Arch Clin Exp Ophthalmol 245:1107-1121

35. Jonas JB, Spandau UH, Harder B, Sauder G (2007) Intravitreal triamcinolone acetonide for treatment of acute nonarteritic anterior ischemic optic neuropathy. Graefes Arch Clin Exp Ophthalmol 245:749-750

36. Kaderli B, Avci R, Yucel A, Guler K, Gelisken O (2007) Intravitreal triamcinolone improves recovery of visual acuity in nonarteritic anterior ischemic optic neuropathy. J Neuroophthalmol 27:164-168

37. Hayreh SS (2008) Intravitreal triamcinolone for nonarteritic anterior ischemic optic neuropathy. J Neuroophthalmol 28:7778

38. Hayreh SS, Zimmerman B, Kardon RH (2002) Visual improvement with corticosteroid therapy in giant cell arteritis. Report of a large study and review of literature. Acta Ophthalmol Scand $80: 355-367$

39. Bennett JL, Thomas S, Olson JL, Mandava N (2007) Treatment of nonarteritic anterior ischemic optic neuropathy with intravitreal bevacizumab. J Neuroophthalmol 27:238-240

40. Hosseini H, Razeghinejad MR (2009) Anterior ischemic optic neuropathy after intravitreal injection of bevacizumab. J Neuroophthalmol 29:160-161

41. Ganssauge M, Wilhelm H, Bartz-Schmidt K-U, Aisenbrey S (2009) Non-arteritic anterior ischemic optic neuropathy (NA-AION) after intravitreal injection of bevacizumab (Avastin ${ }^{\mathbb{R}}$ ) for treatment of angioid streaks in pseudoxanthoma elasticum. Graefes Arch Clin Exp Ophthalmol [in press]

42. Hayreh SS (1981) Anterior ischemic optic neuropathy. V. Optic disc edema an early sign. Arch Ophthalmol 99:1030-1040

43. Kim JE, Mantravadi AV, Hur EY, Covert DJ (2008) Short-term intraocular pressure changes immediately after intravitreal injections of anti-vascular endothelial growth factor agents. Am J Ophthalmol 146:930-934

44. Falkenstein IA, Cheng L, Freeman WR (2007) Changes of intraocular pressure after intravitreal injection of bevacizumab (avastin). Retina 27:1044-1047

45. Hollands H, Wong J, Bruen R, Campbell RJ, Sharma S, Gale J (2007) Short-term intraocular pressure changes after intravitreal injection of bevacizumab. Can J Ophthalmol 42:807-811

46. Semoun O, Blumen-Ohana E, de Preobrajensky N, Nordmann JP (2009) Glaucome aigu par fermeture de l'angle compliquant une injection intravitréenne de bevacizumab. [Acute angle-closure 
glaucoma complicating an intravitreal injection of bevacizumab]. J Fr Ophtalmol 32:58

47. Bakri SJ, McCannel CA, Edwards AO, Moshfeghi DM (2008) Persisent ocular hypertension following intravitreal ranibizumab. Graefes Arch Clin Exp Ophthalmol 246:955-958

48. Kahook MY, Kimura AE, Wong LJ, Ammar DA, Maycotte MA, Mandava N (2009) Sustained elevation in intraocular pressure associated with intravitreal bevacizumab injections. Ophthalmic Surg Lasers Imaging 40:293-295
49. Jalil A, Fenerty C, Charles S (2007) Intravitreal bevacizumab (Avastin) causing acute glaucoma: an unreported complication. Eye 21:1541

50. Wu L, Martinez-Castellanos MA, Quiroz-Mercado H, Arevalo JF, Berrocal MH, Farah ME, Maia M, Roca JA, Rodriguez FJ, PanAmerican Collaborative Retina Study Group (PACORES) (2008) Twelve-month safety of intravitreal injections of bevacizumab (Avastin): results of the Pan-American Collaborative Retina Study Group (PACORES). Graefes Arch Clin Exp Ophthalmol 246:81-87 